\title{
EDITORIAL
}

\section{Fond farewell to clinical utility gene cards}

(C) The Author(s), under exclusive licence to European Society of Human Genetics 2021

European Journal of Human Genetics (2021) 29:1473-1474; https:// doi.org/10.1038/s41431-021-00957-z

Welcome to the October issue of the European Journal of Human Genetics. This month we say farewell to Clinical Utility Gene Cards. After discussion amongst the editorial board and European Society of Human Genetics, it was decided that these should no longer be published. Given the format it was becoming difficult to provide comprehensive information and what was published rapidly became outdated, limiting the usefulness of this format. In some of the final Clinical Utility Gene Cards we will publish, Thomas Mervyn offers an update on oculo-cutaneous albinism and FRMD7 related nystagmus [1, 2].

Amidst a vast increase in utilisation of genome sequencing being performed in clinical practice, researchers continue to work to identify what patients and families value in genome diagnostics. Most studies focus on diagnostic yield of genome sequencing, as a surrogate marker of clinical value. A qualitative interview study of parents confirms that they value a genomic diagnosis, and management plan contingent on this, for their child [3]. However, this study also demonstrates that parents understand the need for genome sequencing to generate evidence on the role of rare genetic variants in causing paediatric disease, to improve diagnostics. Parents identify "benefit" from genome sequencing more broadly than is perhaps appreciated by clinicians.

It is widely accepted that international data sharing is vital for genomic research. Personal data often has to be shared for such research. In the European Union (EU) this is governed by the General Data Protection Regulations (GDPR). To transfer personal data outside of the EU, there must be equivalent data protection offered by the non-EU country. Hallinan and colleagues outline the legal position regarding personal data transfer, how GDPR and court judgements may impair international data sharing for research and offer potential solutions [4].

Mitochondrial impairment is observed in many neurological disorders. Reports in EJHG this month confirm the role of mitochondria in rare, genetic disease. In muscle biopsy from an infant with bi-allelic P4HTM variants, deficient respiratory chain activity was identified [5]. Mitochondrial complex II deficiency is a rare cause of mitochondrial disease. Lin and colleagues provide further evidence of the role of bi-allelic $S D H D$ variants in this condition [6]. These papers provide important information on the differential diagnosis of mitochondrial disorders and how genome sequencing can aid diagnosis.

The genomics literature is full of papers describing novel approaches to help interpret genetic variants. When Webb et al identified a child with bi-allelic variants in KCNJ16 they were unsure of the clinical implications [7]. When they identified similarities between the phenotype of their patient and a KCNJ16 null mouse, it helped clinch the diagnosis.
Genome sequencing technologies are helping us to understand the spread of human populations. Genetic markers on the $\mathrm{Y}$-chromosome can be used to trace population expansions and movement. Rare genetic markers on the Y-chromosome of populations in North Eastern Europe are suggested to indicate possible influx directions of population migration. Ashraf and Lawson suggest that since most genome studies mapping complex traits have been performed in populations who experienced the "out-of-Africa" bottleneck, this could lead to bias due to confounding between genetic drift and genetic selection [8]. This is a further argument for the need for genomic studies in underrepresented populations. Maceda and colleagues use high coverage genome sequencing to identify evidence that geographical barriers influence population genetics in the Spanish Pyrenees-a further example of a geographic "bottle neck" [9].

\author{
Alisdair McNeill ${ }^{1,2}$ \\ ${ }^{1}$ Department of Neuroscience, The University of Sheffield, Sheffield, \\ UK. ${ }^{2}$ Sheffield Clinical Genetics Department, Sheffield Children's \\ Hospital NHS Foundation Trust, Sheffield, UK. ${ }^{凶}$ email: $a$. \\ moneill@sheffield.ac.uk
}

\section{REFERENCES}

1. Aamir A, Kuht HJ, Grønskov K, Brooks BP, Thomas MG. Clinical utility gene card for oculocutaneous (OCA) and ocular albinism (OA) -an update. Eur J Hum Genet. 2021. https://doi.org/10.1038/s41431-021-00809-w.

2. Dawar B, Kuht HJ, Han J, Maconachie GDE, Thomas MG. Clinical utility gene card for FRMD7-related infantile nystagmus. Eur J Hum Genet. 2021. https://doi.org/ 10.1038/s41431-021-00826-9.

3. Pollard S, Weymann D, Dunne J, Mayanloo F, Buckell J, Buchanan J, et al. Toward the diagnosis of rare childhood genetic diseases: what do parents value most? Eur J Hum Genet. 2021. https://doi.org/10.1038/s41431-021-00882-1.

4. Hallinan D, Bernier A, Cambon-Thomsen A, Crawley FP, Dimitrova D, Medeiros CB, et al. International transfers of personal data for health research following Schrems II: a problem in need of a solution. Eur J Hum Genet. 2021. https://doi.org/10.1038/ s41431-021-00893-y.

5. Hay E, Wilson LC, Hoskins B, Samuels M, Munot P, Rahman S. Biallelic P4HTM variants associated with HIDEA syndrome and mitochondrial respiratory chain complex I deficiency. Eur J Hum Genet. 2021. https://doi.org/10.1038/s41431-02100932-8.

6. Lin S, Fasham J, Al-Hijawi F, Qutob N, Gunning A, Leslie JS, et al. Consolidating biallelic SDHD variants as a cause of mitochondrial complex II deficiency. Eur J Hum Genet. 2021. https://doi.org/10.1038/s41431-021-00887-w.

7. Webb BD, Hotchkiss H, Prasun P, Gelb BD, Satlin L. Biallelic loss-of-function variants in KCNJ16 presenting with hypokalemic metabolic acidosis. Eur J Hum Genet. 2021. https://doi.org/10.1038/s41431-021-00883-0.

8. Ashraf B, Lawson DJ. Genetic drift from the out-of-Africa bottleneck leads to biased estimation of genetic architecture and selection. Eur J Hum Genet. 2021. https:// doi.org/10.1038/s41431-021-00873-2.

9. Maceda I, Álvarez MM, Athanasiadis G, Tonda R, Camps J, Beltran S, et al. Fine-scale population structure in five rural populations from the Spanish Eastern Pyrenees using high-coverage whole-genome sequence data. Eur J Hum Genet. 2021. https://doi.org/10.1038/s41431-021-00875-0. 
1474

AUTHOR CONTRIBUTIONS

Dr Alisdair McNeill conceived and wrote this editorial.

ADDITIONAL INFORMATION

Correspondence and requests for materials should be addressed to Alisdair MCNeill.
Reprints and permission information is available at http://www.nature.com/ reprints

Publisher's note Springer Nature remains neutral with regard to jurisdictional claims in published maps and institutional affiliations. 